\title{
Falibilismo duro y falibilismo pragmático: Un alegato en pro de la posible falsedad de cualquier creencia $^{1}$
}

\author{
Mario Gensollen \\ Departamento de Filosofía \\ Universidad Autónoma de Aguascalientes \\ mgenso@correo.uaa.mx
}

A partir de los escritos de Popper y Peirce, el falibilismo ha sido una posición que ha ocupado un lugar central en el actual debate epistemológico y ético. La defensa de la tesis falibilista se ha convertido en una de las vías más atractivas para combatir los embates dogmáticos y escépticos. A pesar de que el falibilismo parezca una forma de concesión al reto escéptico, por el contrario, es quizá una de las pocas salidas que nos quedan para defender y fundamentar la tolerancia a la que aspira una sociedad democrática.

Sin embargo, no es hasta Wittgenstein y el nuevo pragmatismo ${ }^{2}$ que la tesis falibilista ha sido purificada de sus inicios quizá ingenuos. Esto, de inicio, puede sonar extraño. Se sabe que algunas de las cualidades más marcadas del modo de filosofar de Wittgenstein son su rigor lingüístico y su descrédito de las teorías a favor de las descripciones. Decir que Wittgenstein sostuvo algo así como una «posición falibilista» contradeciría los principales rasgos de su pensamiento. Por ello, vale la pena hacer un par de aclaraciones.

En primer lugar, se sabe que las palabras-ismos indican algo así como una actitud desmesurada del juicio que termina por desvir-

${ }^{1}$ Este texto ha sido escrito como una réplica tardía y fuera de contexto al estimulante y agudo artículo «Por qué no soy falibilista» de Guillermo Hurtado (2002). Varias versiones anteriores fueron leídas en diversos foros. Agradezco los comentarios de Carlos Pereda, Gustavo Ortíz, Jorge Tagle, Luis Xavier López-Farjeat y José Luis Rivera.

2 Me refiero principalmente al pensamiento de Richard Bernstein (2006), y a las bases pragmatistas clásicas - en especial a partir de John Dewey - sobre la que éste se construye. 
tuar aquello que es juzgado ${ }^{3}$. Cuando decimos que alguien, por poner sólo un caso, es un «moral-ista», lo que decimos es que su actitud judicativa es desmesurada con respecto a la moral. Como otra palabra-ismo — «fanatismo», «nacionalismo», «puritanismo», u otras más claras como «alcoholismo»- el falibilismo parecería inducirnos a sospechar una especie de desmesura. Sin embargo, esta coincidencia sintáctica, como mostraré, no tiene trasfondo semántico. Por el contrario, al falibilismo, como actitud judicativa, le es esencial la mesura. Justo por ello podemos decir que es el término medio virtuoso entre los extremos viciosos del dogmatismo y el escepticismo.

En segundo lugar, suele ser una simplificación burda el afirmar que Wittgenstein es ajeno a cualquier forma de teoría. Es cierto que Wittgenstein desacredita cualquier forma de teoría que pretenda representar cómo son las cosas con pretensiones sistemáticas, definitivas y nomológicas (ver Philosophische Untersuchungen 87, en adelante $P U)$. Sin embargo, si tomamos el término «teoría» en un sentido mucho más austero, como posibles descripciones que iluminan relaciones, sin duda Wittgenstein usó «teorías». En este sentido austero del término, se podría afirmar que las teorías son instrumentos que empleamos para interactuar en la práctica con la realidad (ver Quintanilla 2007; 69). El falibilismo wittgensteiniano es, sólo en este sentido restringido, una teoría, o bien, una actitud (Meinung) con trasfondo conceptual. Dejo los detalles para más adelante.

En lo que sigue, mi argumentación será presentada en tres partes: en primer lugar, reconstruiré brevemente la actitud falibilista wittgensteiniana, contrastándola con el naturalismo humeano y strawsoniano; en segundo lugar, haré frente a una crítica habitual al falibilismo como una posición revisionista, argumentado que el falibilismo, lejos de ser una posición revisionista, es una actitud contingentista; por último, haré frente a algunas objeciones que pueden hacerse al falibilismo desde la teoría de la argumentación. 


\section{El falibilismo wittgensteiniano}

La forma más general de enunciar la tesis falibilista es la siguiente: cualquiera de mis creencias puede ser falsa. Así enunciada, la tesis falibilista presenta innumerables problemas. Pero, al menos por ahora, quedémonos un momento con esta formulación general. Así, podríamos llamar «posición antifalibilista» a aquella que sostenga una versión parecida a la siguiente tesis: al menos algunas creencias nuestras no son posiblemente falsas, o bien, son necesariamente verdaderas. En el debate contemporáneo, el naturalismo strawsoniano - de la mano de sus controvertidas interpretaciones de Wittgenstein y Hume- puede ser concebido como de los más fuertes partidarios de la tesis antifalibilista. Por ello, será la postura principal contra la cual argumentaré. Primero, comenzaré por reconstruir las líneas principales de su posición.

Para Wittgenstein, al igual que para Hume - piensa Strawson-, hay una diferencia entre aquellas proposiciones que son susceptibles de ser cuestionadas y decidirse a la luz de la razón, y aquellas que no lo son, pues están exentas de duda. Hay una distinción, pues, entre lo que es vano someter a cuestionamiento y debemos dar por sentado en todos nuestros razonamientos, y entre lo que es objeto genuino de cuestionamiento. Para ir detallando la posición que atribuye a Wittgenstein, Strawson recurre a una serie de afirmaciones y frases que Wittgenstein usa continuamente en Über Gewissheit (En adelante UG). Por ejemplo:

Podría decirse: «'Sé' expresa la seguridad tranquila (beruhigte), no la que todavía está en lucha» (UG 357).

Ahora bien, me gustaría considerar tal seguridad no como algo parecido a la precipitación o a la superficialidad, sino como (una) forma de vida. (Esto está muy mal expresado y, posiblemente, también mal pensado) (UG 358).

Pero ello significa que quiero considerarlo como algo que yace más allá de lo justificado e injustificado; como, por decirlo de algún modo, algo animal (UG 359). 
Strawson no desperdiciará los ecos humeanos que resuenan detrás de estos parágrafos. Aunque Wittgenstein no apele abiertamente a la naturaleza para dar cuenta de la formación de ciertas creencias, ello no implica que su postura no sea igualmente naturalista. Por el contrario, como se advierte en la frase «algo animal», parece que Wittgenstein estaría sugiriendo que la creencia tiene más que ver, como afirma explícitamente Hume en el Treatise, con la parte sensitiva que con la parte cogitativa de la naturaleza humana.

Continuando con las coincidencias, Strawson dará otro paso. Al igual que Hume, Wittgenstein parece negar la relevancia de ciertas dudas en el contexto de nuestra vida práctica. En otras palabras, el escepticismo parece nulificarse, a nivel del pensamiento empírico cotidiano, frente a ciertas creencias que forman el eje de nuestra vida efectiva. Basta con echar un vistazo a un par de parágrafos más:

Es decir, las preguntas (Fragen) que hacemos y nuestras dudas (Zweifel), descansan sobre el hecho de que algunas proposiciones están fuera de duda, son - por decirlo de algún modo - los ejes sobre los que giran aquéllas (UG 341).

Es decir, el que en la práctica (in der Tat) no se pongan en duda ciertas cosas pertenece a la lógica de nuestras investigaciones científicas (UG 342).

Hasta este punto, no podemos negarlo, las coincidencias entre Hume y Wittgenstein resultan evidentes, con las salvedades de la terminología y los matices particulares. Sin embargo, en el segundo parágrafo citado ya se empieza a destacar una veta no precisamente humeana. Parece, de entrada, que Wittgenstein ya no sólo habla de creencias que damos por sentadas en la vida cotidiana, en el ámbito práctico, sino también en el teórico. La analogía entre los dos polos de la brecha abierta por Hume - la vida cotidiana y la investigación teórica -, parece dar un anticipo de su posible cierre.

Para Wittgenstein, según Strawson, es posible realizar un análisis de nuestro sistema de creencias que proporcione de manera medianamente nítida una diferencia entre aquellas creencias que son el trasfondo, andamiaje o entramado, sobre el cual se apoya el resto: «Sin embargo, son ellas las que dan forma a nuestras con- 
sideraciones y a nuestras investigaciones. Es posible que alguna vez hayan sido objeto de controversia. Pero también es posible que desde tiempos inmemoriales pertenezcan al andamiaje (Gerüst) de todas nuestras consideraciones. (Todo ser humano tiene padres)» (UG 211). Así, comentará Strawson, el objetivo de Wittgenstein, «por lo menos en parte, es el de dar cuenta u ofrecer una descripción de cómo son realmente nuestros sistemas o cuerpos de creencias humanos» $(2003 ; 60)$.

Hasta aquí, la lógica de la interpretación strawsoniana parece impecable. Pero, a partir de este punto, las cosas empiezan a complicarse. Veamos el punto de desequilibrio, en palabras del mismo Strawson:

Wittgenstein no representa esta distinción entre dos tipos de elementos en nuestros sistemas de creencias como una distinción nítida, absoluta e inmodificable; todo lo contrario. Sin duda, esto es un punto a su favor, a la vista de algunos de sus ejemplos de proposiciones de la segunda clase: de proposiciones que se hallan «exentas de duda». (Cuando escribe en 1950-51 ofrece como ejemplo la proposición de que nadie ha estado muy lejos - por ejemplo, a una distancia como de la tierra a la luna - de la superficie de la tierra) $(2003 ; 61)$.

A diferencia de Hume, que concebía la existencia del mundo material y la fiabilidad de la inducción como creencias inconmovibles, Wittgenstein agrega un elemento dinámico en la distinción entre creencias exentas de duda y creencias que podemos poner en cuestión, además de que no se limita a estas dos creencias mencionadas. Sin embargo, el punto de incoherencia en la interpretación strawsoniana viene con la siguiente afirmación:

[...] el entramado es concebido, hasta cierto punto al menos, de una manera dinámica: lo que una vez fue parte del entramado puede cambiar de condición, puede asumir el carácter de una hipótesis que habrá de ser cuestionada y, quizás, falsada - algunas de las que ahora veríamos como suposiciones sobre agentes o poderes sobrenaturales probablemente entren en esta categoría - mientras que otras partes del entramado permanecen fijas e inalterables (2003; 63-4). 
Por un lado, Strawson afirma que Wittgenstein no representa de manera nítida o absoluta la distinción entre creencias exentas de duda y creencias que podemos poner en cuestión; por otro, en consonancia con el anterior, que Wittgenstein agrega un elemento dinámico en la distinción, por lo que creencias que en algún momento o circunstancia pueden fungir como parte del entramado en el cual se sujetan las demás creencias, en otra situación pueden dejar de serlo. Sin embargo, el elemento desconcertante se presenta cuando afirma que otras partes del entramado permanecen fijas e inalterables, como si el elemento dinámico introducido por Wittgenstein las dejara intactas e inamovibles en cualquier momento, situación o circunstancia concreta. A pesar de ello, Strawson es incapaz de mencionar ejemplos concretos que proporcione Wittgenstein de este tipo de creencias. El mismo Strawson asegura que, de dichas creencias, no se puede dar una lista, aunque sí es capaz de sugerir algunas (ver Strawson 1997). Pero el punto es que, cuando lo hace, deja de hablar de Wittgenstein y es él quien hace uso de la palabra. Esto queda muy claro con la siguiente afirmación:

Resulta coherente con la aversión extrema que muestra Wittgenstein en su obra tardía a cualquier tratamiento sistemático de los asuntos el que nunca intentara especificar qué aspectos de nuestra imagen del mundo, de nuestros sistemas de referencia «no están sujetos a alteración o sólo a una imperceptible»; qué aspectos se mantienen firmes, o puede darse por descontado que seguirán manteniéndose firmes, a través de todas las revoluciones del pensamiento científico o del desarrollo social, debido al profundo compromiso humano o natural que tenemos con ellos. Hasta ahora, los aspectos que se han mencionado de manera específica, o en los que nos hemos detenido en mayor o menor grado, son los que tienen relevancia -o muestran irrelevancia - en relación con los problemas escépticos tradicionales: lo que respecta a la existencia de los cuerpos, el conocimiento de otras mentes y la práctica de la inducción. Ahora no voy a intentar compilar una lista, o adentrarme en una labor metafísica conectiva mostrando las relaciones e interdependencias de los elementos de la estructura general $(2003 ; 74-5)$.

Antes de sugerir por qué, en mi opinión, la lectura que hace Strawson de Wittgenstein es incorrecta e interesada, creo oportuno 
valorar la teoría propia de Strawson respecto a la aparente existencia de creencias estables e inamovibles dentro del plexo básico de nuestro sistema de creencias. Para ello, utilizaré ambos ejemplos que da por sentado Strawson en consonancia abierta con Hume - el caso de la existencia del mundo material y la fiabilidad de la inducción -, y uno de los que curiosamente parece dar Wittgenstein - todo ser humano tiene padres.

Primero, la existencia del mundo material. Imaginemos, en cierta conexión con la hipótesis de los cerebros en una cubeta, que somos seres humanos conectados a un ordenador que nos provee de todas las experiencias que en conjunto consideramos fruto de nuestra interacción con un mundo material. Si algún día, un hombre lograse, quizá no por merito propio, sino por un error del sistema, salir de ese mundo virtual, al menos, de entrada, revaloraría su concepto de «mundo material». ¿Qué sucede en este caso con la creencia, aparentemente inconmovible e inalterable, en la existencia del mundo material? Si este hombre lograse escapar del mundo virtual, podría contestar Strawson, seguiría dando por sentada dicha creencia, ahora en relación con el nuevo mundo. Sin embargo, no estaría tan seguro de que eso sucediera necesariamente. De inicio, ahora ya no sería la naturaleza la que impondría dicha creencia. Podría ser que el sujeto en cuestión ya se anduviera con cuidado en darla por supuesta. Ahora sería su razón la que le llevaría a adoptar dicha creencia, y la certeza de antaño se vería seriamente mermada. Lo que sí estaría dispuesto a aceptar, con Strawson, es que incluso en esas circunstancias habría una serie de creencias que el sujeto daría por supuestas y constituirían un nuevo entramado en el que las otras creencias se apoyarían ${ }^{4}$.

Ahora, el caso de la fiabilidad de la inducción. Muy en consonancia con los ejemplos que suelen aducir los filósofos interesados en el tema de la justificación epistémica, imaginemos que nos enteramos que hemos sido, desde nuestro nacimiento, sujetos de un experimento de un científico, el cual ha alterado, mediante

4 Este es el núcleo de la postura de Donald Davidson contra el escepticismo. Ver Hurtado 1989 . 
un invento siniestro, la eficacia de nuestro razonamiento inductivo. Supongamos también, que al enterarnos, además de enojo e indignación, comprendemos el hecho perfectamente, pues en nuestra vida hemos fallado incontables ocasiones en cuestiones prácticas que involucraban una inducción adecuada. En adelante, después de apresar al científico lunático, nos llevan con una serie de especialistas para valorar nuestros casos concretos. Algunos de ellos sugieren que el mal causado a nuestro razonamiento inductivo puede ser subsanado con cierta terapia; otros, que el daño es irreversible. Dado que en estas circunstancias más vale intentarlo que darse por vencido, nos sometemos a la terapia, pero no sabemos con certeza si ésta tendrá éxito. En tal situación imaginaria, después de la terapia ¿daríamos por supuesta la fiabilidad de nuestras inducciones? Aunque, incluso en dicho caso, daríamos por supuestas ciertas creencias, del mismo modo que en el caso anterior.

Por último, el ejemplo wittgensteiniano. Imaginemos que hemos vivido toda nuestra vida dentro de una instalación científica y que se nos ha dicho que el mundo exterior ha sido contaminado por un virus que ha aniquilado toda vida existente. Por ello, llevamos rutinariamente nuestra vida dentro de las instalaciones y nunca nos pasa por la cabeza salir de ellas, pues eso implicaría nuestra muerte. Si en alguna ocasión, un sujeto saliera de las instalaciones por accidente, y se diera cuenta de que en el mundo exterior no hay algo como un virus mortal, y que de hecho muchas personas viven fuera de las instalaciones en las que ha llevado su vida, empezaría a cuestionar un conjunto, antes supuesto, de creencias del entramado. Pero veamos el caso de la creencia «tengo padres». Sigamos imaginando que ese sujeto investiga por qué le han engañado, y descubre que es un clon, y que su estancia en las instalaciones tiene que ver con que el mundo no puede enterarse de su existencia. En este momento, el individuo en cuestión dejará de dar por sentado que tiene padres $\mathrm{o}$, a lo menos, modificará de manera radical su concepto de «tener padres».

En estas tres posibilidades lógicas subyacen premisas que podrían ser cuestionadas, no sin cierta ingenuidad. Alguien podría contraargumentar que: 
a) en el caso del mundo material, se sigue suponiendo la creencia en el mundo material, aunque no sea con respecto al ficticio, sino al nuevo que se abre ante los ojos. Contra esto, bien cabe simplemente radicalizar un poco más el ejemplo. Si eso le pasara al sujeto treinta veces, supongo con cierta probabilidad de que ya no la daría más por supuesta en sus razonamientos y acciones;

b) en el segundo caso, bien se podría contraargumentar algo parecido, a lo que tendríamos que radicalizar también el ejemplo;

c) en cuanto al tercer ejemplo, se nos presenta una situación interesante. Alguien bien podría sugerir que el sujeto modificaría simplemente el contenido de la creencia «tengo padres», no dejando de suponer dicha creencia. Ahora, «tener padres» ya no significaría que un hombre y una mujer me concibieron mediante un acto sexual, sino que fui clonado, y mi padre o madre es el sujeto del cual copiaron mi carga genética. Contra esta crítica ingenua, simplemente habría que decir que el contenido semántico de la creencia determina la creencia; si cambiamos el contenido semántico, dicha creencia es otra creencia respecto de la original.

A partir de estas tres posibilidades lógicas ${ }^{5}$ se concluye que cualquier creencia de nuestro sistema de creencias puede ser falsa. No así su contorno. El sistema mismo es el que posibilita la aparición o desaparición de alguna creencia. Es dentro de un marco, y sólo dentro de él, que podemos creer o descreer algo. La mutabilidad de nuestro sistema de creencias implica la posible falsedad de cualquier creencia, que a su vez implica la no existencia de verdades necesarias. Sin embargo, no hay que confundir - una trivialidad muchas veces ignorada- que la negación de la verdad necesaria

${ }^{5}$ No pienso que sea el lugar indicado para discutir la distinción que hace Putnam entre posibilidades físicas y posibilidades conceptuales (ver Putnam 1988, 13-33). Me contento, en este momento, con la posibilidad lógica, pues pienso que para la verdad del argumento que presento las críticas y distinciones de Putnam resultan intrascendentes. 
de cualquier creencia no implica la negación de la necesaria posibilidad de algunas creencias. En otras palabras, no es lo mismo necesidad que necesaria posibilidad.

Regresando al hilo conductor de la argumentación, ¿cuál es, pues, el error de Strawson? Creo oportuno, para detectar la anomalía en la postura strawsoniana, mencionar el argumento que aduce Strawson para demostrar que existen ciertas creencias de nuestro entramado inalterables bajo cualquier circunstancia. $\mathrm{O}$, en otras palabras, su argumento contra el historicismo:

La imagen humana del mundo está sujeta a cambios, por supuesto. Pero sigue siendo una imagen del mundo humana; una imagen de un mundo de objetos físicos (de cuerpos) en el espacio y en el tiempo, que incluye observadores humanos capaces de acción y de adquirir e impartir conocimiento (y error) tanto sobre ellos mismos como unos sobre otros y sobre el resto de cuanto puede ser encontrado en la naturaleza. Gran parte de la concepción constante, de lo que, en palabras de Wittgenstein, «no está sujeta a alteración o sólo a una imperceptible», viene dada a la vez que la idea misma de alteración histórica en la visión del mundo humana $(2003 ; 74)$.

¿A qué se refiere Strawson, en el argumento anterior, con imagen humana del mundo?, y ¿qué cree que la constituye? Strawson parece decir que hay una serie de creencias, inalterables tanto en el pasado, como en el presente y en cualquier posible futuro, que configuran nuestra imagen del mundo, o del mundo tal cual lo concibe cualquier ser humano. Para Strawson, esta imagen humana del mundo está configurada por una serie finita e inalterable de creencias.

El argumento de Strawson parece eficaz en el punto en el que afirma la existencia de una imagen humana del mundo. Todos podríamos aceptar su existencia. Sin embargo, el error strawsoniano radica en el contenido que pretende darle. Para Wittgenstein no es ninguna serie finita de creencias la que constituiría la imagen humana del mundo, sino el hecho general de que en cualesquiera circunstancias existen creencias que damos por sentadas, aunque estas creencias no sujetas a duda pueden variar en una circunstancia o en otra.

En otras palabras, el error de Strawson radica en una confusión 
radical entre la generalidad del hecho concerniente a la suposición constante de ciertas creencias no sujetas a duda, y en creer que ciertas creencias siempre están presentes en nuestra imagen del mundo. De la primera tesis no se sigue la segunda. El argumento de Strawson da un paso indebido entre ambas.

\section{El falibilismo como actitud contingentista}

De lo anterior se sigue que, a partir de Wittgenstein, podemos adoptar una actitud falibilista. Es claro, como lo mencioné en un principio, que es suficientemente arriesgado atribuir teorías o posiciones teóricas sustantivas a Wittgenstein. Wittgenstein siempre fue muy cuidadoso de distinguir opinión (Einstellung) de actitud (Meinung). Cuando hablo de falibilismo, no estoy pensando en opiniones, sino en actitudes.

Como mencioné en la parte precedente, existe una formulación general y ambigua de la tesis falibilista: cualquiera de nuestras creencias puede ser falsa. Aquí los problemas surgen inmediatamente.

Hace algunos años Guillermo Hurtado publicó un artículo suficientemente provocativo al respecto (ver 2002; 175-206). En él, Hurtado defiende con mucha elegancia una posición antifalibilista. Sin embargo, sus argumentos sólo atacan una versión dura, y por tanto ingenua, del falibilismo. Para Hurtado, el falibilismo es una posición revisionista y, por tanto, que atenta contra el sentido común. Sintetizando al extremo su argumentación, su principal queja contra el falibilismo radica en la suposición de que éste implicaría que cualquiera de nuestras creencias puede ser revisada, lo cual resulta imposible, pues para revisar una creencia debemos dar por supuesta la verdad de otras creencias que fungen como criterios o parámetros para la revisión. Si estoy en lo correcto, ésta es la médula de la argumentación de Hurtado ${ }^{6}$.

${ }^{6}$ Estoy consciente que es una interpretación apresurada del magnífico texto de Guillermo Hurtado, pero lo que me interesa resaltar principalmente es su afirmación de que el falibilismo es una tesis revisionista, al margen de otros argumentos sumamente interesantes que esgrime en su texto. 
El problema es el siguiente. Es cierto que de la tesis «cualquiera de nuestras creencias puede ser falsa» se sigue que «cualquiera de nuestras creencias puede ser revisada». Sin embargo, el argumento de Hurtado implícitamente supone un agregado a la segunda tesis, a saber que «todas nuestras creencias pueden ser revisadas al mismo tiempo y bajo las mismas circunstancias». Esta tercera tesis no se sigue necesariamente de la tesis falibilista general $\mathrm{y}$, estoy de acuerdo con Hurtado, atenta contra el sentido común y es falsa. Este falibilismo duro e ingenuo no es el que se puede adoptar a partir de las consideraciones de Wittgenstein.

A partir de Wittgenstein podemos adoptar una actitud falibilista pragmática ${ }^{7}$. Me explico. Wittgenstein, al introducir un elemento dinámico en nuestra imagen humana del mundo, implícitamente parece sostener que cualquiera de nuestras creencias puede ser falsa, y por tanto revisada, pero no todas al mismo tiempo ni bajo las mismas circunstancias. Una creencia que en un primer momento es dada por supuesta, y que puede fungir como criterio o parámetro para la revisión de otra, en un segundo momento puede ser revisa$\mathrm{da}$, aunque en este segundo momento daremos por supuestas otras creencias que fungirán como parámetros o criterios para la revisión de dicha creencia.

Descontextualizaré un poco una de las imágenes que para hablar del lenguaje Wittgenstein utiliza en las $P U$, para hablar aquí de nuestro sistema de creencias. Dice Wittgenstein:

Nuestro lenguaje puede verse como una vieja ciudad: una maraña de callejas y plazas, de viejas y nuevas casas, y de casas con anexos de diversos períodos; y esto rodeado de un conjunto de barrios nuevos con calles rectas y regulares y con casas uniformes ( $P U 18)$.

Imaginemos que esta ciudad wittgensteiniana es nuestro sistema de creencias: las partes viejas conviven con las nuevas $y$, tarde o temprano, por qué no, al igual que el barco de Neurath, de la ciudad de antaño pueden ya no quedar ni los cimientos, siendo, a

7 Aunque lo usa en otro contexto y para otros fines, mi formulación del «falibilismo pragmático» es muy cercana a la de Richard Bernstein (ver 2006; 11). 
la vez y paradójicamente, la misma ciudad. Pero, y he aquí la analogía, aunque ya no quedasen ni los cimientos de la antigua ciudad, seguramente seguirán habiendo calles y casas, o cosas que se parezcan a calles, casas, barrios, locales comerciales, etcétera.

En otras palabras, el falibilismo no es una postura revisionista, como supone Hurtado, sino una actitud contingentista. Lo que interesa defender desde una actitud falibilista pragmática no es que nuestras creencias - cualquiera de ellas - sean revisables, sino que no deberíamos actuar como si hubiera verdades necesarias. Debemos actuar como si toda verdad fuera contingente, o bien, como si ninguna de nuestras creencias fuera necesariamente verdadera y sí posiblemente falsa. Es éste, a mi parecer y a partir de Wittgenstein, el núcleo de una actitud falibilista. Nada más humano que el reconocimiento pragmático de nuestra contingencia.

\section{Falibilismo y razón enfática}

Quizá a algunos teóricos de la argumentación podría parecerles que el falibilismo es una posición teórica que sucumbe ante un vértigo complicador, o bien que sede ante la tentación escéptica de la ignorancia ${ }^{8}$. Sin embargo, y otra vez, el blanco es la posición falibilista dura o ingenua.

En primer lugar, debemos notar que una actitud falibilista pragmática no viola, como sí lo hace la posición falibilista dura o ingenua, esa regla constitutiva procedimental de los ciclos argumentales que es la presunción (ver Pereda 1994; 51). Las presunciones no siempre son las mismas, porque no siempre estamos ubicados en el mismo sitio dentro del ciclo argumental. Además, las presunciones, como su sentido ordinario lo indica, no son convicciones en sentido fuerte, ni tampoco nos llevan al fundamentalismo. Realizar presunciones es un presupuesto básico de cualquier argumentación, pues toda argumentación se realiza en medio y nunca al principio de un proceso cognoscitivo. 
En segundo lugar, una actitud falibilista pragmática no sucumbe ante la tentación de la ignorancia (escepticismo). Actuar como si cualquiera de nuestras creencias pudiera ser falsa, por la sencilla razón de que actuamos como si no existieran verdades necesarias, no implica negar que muchas veces llegamos a creencias que, de hecho, son verdaderas. Por el contrario, el falibilismo pragmático nos inmuniza contra cualquier tentación de la certeza (dogmatismo).

Termino con algo así como una provocación. Carlos Pereda, a través del estudio de los vértigos argumentales, ha elaborado una fenomenología de la experiencia argumental para defender la incertidumbre de la razón. Pereda contrapone la razón austera - propia del cálculo, la semántica unívoca, la exactitud - a la razón enfática - aquélla que admite el lenguaje figurado y la probabilidad, y que toma en cuenta tanto la historia de los conceptos, como considera relevante quién dice una cosa y a quién la dice-. Hacia el final de la obra nos sugiere que la mejor defensa de la razón es la defensa de una razón enfática (ver 1994; 320). Pues bien, pienso que la defensa de una actitud falibilista pragmática es la mejor defensa de una razón enfática.

\section{Bibliografía}

BernsteIn, Richard. 2006. El abuso del mal. La corrupción de la política y la religión desde el 11/9 (Alejandra Vassallo e Inés Weinstabl Trads.). Buenos Aires: Katz.

Hurtado, Guillermo. 1989. «Ward on Davidson's Refutation of Scepticism», Crítica 63: 75-81.

Hurtado, Guillermo. 2002. «¿Por qué no soy falibilista?». En Carlos Pereda y Julio Beltrán (eds.), La certeza, ¿un mito? Naturalismo, falibilismo y escepticismo. México: IIF/UNAM: 175-206.

Pereda, Carlos. 1994. Vértigos argumentales. Una ética de la disputa.

Barcelona: Anthropos/UAM Iztapalapa.

Pereda, Carlos. 1998. Sueños de vagabundos. Un ensayo sobre filosofia, moral y literatura. Madrid: Visor.

Putnam, Hilary. 1988. Razón, verdad e historia (José Miguel Esteban Cloquell Trad.). Madrid: Tecnos. 
Quintanilla, Pablo. 2007. «Wittgenstein y la autonomía de la voluntad: la presencia del pragmatismo», Revista de Filosofía, vol. 25, no. 56: 67-104.

Strawson, Peter. 2003. Escepticismo y naturalismo: algunas variedades (Susana Badiola Trad.). Madrid: Mínimo Tránsito/Antonio Machado Libros.

Strawson, Peter. 1997. Análisis y metafísica. Una introducción a la filosofía (Nieves Guasch Trad.). Barcelona: Paidós.

Wittgenstein, Ludwig. 2000. Sobre la certeza. Über Gewissheit (Josep Lluís Prades y Vicent Raga Trads.). Barcelona: Gedisa.

Wittgenstein, Ludwig. 1988. Investigaciones filosóficas. Philosophische Untersuchungen (Alfonso García Suárez y Ulises Moulines Trads.). Barcelona: UNAM/IIF/Crítica.

\section{RESUMEN}

El propósito de este artículo es defender una versión modificada (pragmática) de la tesis falibilista: debemos actuar como si cualquiera de nuestras creencias pudiera ser falsa. El autor argumenta, a partir de Wittgenstein, que el falibilismo pragmático, lejos de ser una teoría, es una actitud: la actitud en la que se fundamentan las bases de una sociedad democrática, lejos de los extremos viciosos del digmatismo y el escepticismo.

Palabras clave: Wittgenstein; Strawson; falibilismo; dogmatismo; escepticismo.

\section{ABSTRACT}

The aim of this paper is to defend a modified version (pragmatic version) of falibilism: we must act like either of our beliefs could be false. The author argues, with Wittgenstein, that pragmatic falibilism is not a theory, is an attitude: the attitude that supports the basis of a democratic society, far from the dogmatism and skepticism.

Key words: Wittgenstein; Strawson; falibilism; dogmatism; skepticism. 
